LETTER TO THE EDITOR

\title{
Late relapse in the neck: considerations from a case of seminoma and review of the literature
}

\author{
Recidiva linfonodale cervicale tardiva: spunti di riflessione da un caso di seminoma \\ e revisione della letteratura
}

\author{
Virginia Corazzi', Remo Accorona², Rosa Negro ${ }^{3}$, Luca Calabrese ${ }^{4}$ \\ ${ }^{1}$ ENT Department, University Hospital of Ferrara, Ferrara, Italy; ${ }^{2}$ Department of Otorhinolaryngology - Head and Neck Surgery, \\ Fondazione IRCCS Ca' Granda, Ospedale Maggiore Policlinico, Milano, Italy; ${ }^{3}$ Department of Pathology, "San Maurizio" Hospital, \\ Bolzano, Italy; ${ }^{4}$ Division of Otorhinolaryngology, "San Maurizio" Hospital, Bolzano, Italy
}

KEY WORDS: seminoma, testicular neoplasm, lymphatic metastasis, cancer of unknown primary, neck dissection

PAROLE CHIAVE: seminoma, neoplasia testicolare, metastasi linfatica, carcinoma a primitività ignota, svuotamento laterocervicale

\section{Dear Editor,}

Differential diagnosis of neck lumps is a routine issue in daily ENT practice. However, in case of adenopathy from cancer of unknown primary it may be very challenging, and integration between medical history and clinical, radiological, and cytological findings becomes fundamental.

We present a case of a very late recurrence of a seminoma in cervical nodes, occurring more than 20 years after the primary treatment, together with a review of the scientific literature.

A 59-year-old man presented to our attention with left indolent neck swelling, which had increased progressively over 6 months. It was a huge mass at level VB, fixed to underlying tissues, with intact overlying skin. In the patient's clinical history, a left testicular seminoma treated with surgery and adjuvant chemotherapy 20 years earlier was reported. No lesions of the upper aerodigestive tract (UADT) were found after pan-endoscopic examination in white light and narrow band imaging. Neck ultrasound (US) and contrast-enhanced neck-chest computed tomography (CT) showed a $5 \mathrm{~cm}$ left colliquated adenopathy in level $\mathrm{VB}$, and other adenopathies in left level III and VA (Fig. 1A), without radiological signs of extracapsular nodal extension.

Total-body fluorodeoxyglucose positron emission tomography (PET) highlighted the presence of the multiple hypermetabolic adenopathies, from level II to $\mathrm{V}$ without other findings.

Fine needle aspiration cytology (FNAC) of the largest adenopathy showed necrotic material mixed with poorly differentiated large-sized cells, positive for cytokeratin (CK) CAM 5.2 and CK7, and negative for CK20, TTF1, p40, SOX10, p16 and EBV, which was therefore consistent with neck metastasis from a poorly differentiated carcinoma.

The tumour was staged as cTxN2bM0 (according to TNM staging system $8^{\text {th }}$ edition), and consequently, under general anaesthesia, pan-endoscopy of the UADT (resulted macroscopically negative for disease) and left level II to V dissection were performed.
Received: September 28, 2019

Accepted: February 10, 2020

\author{
Correspondence \\ Virginia Corazzi \\ ENT Department, University Hospital of Ferrara, \\ via Aldo Moro 8, 44124 Ferrara (Cona), Italy \\ Tel. +390532236317 \\ E-mail: virginia.corazzi@unife.it \\ Funding \\ None. \\ Conflict of interest \\ The Authors declare no conflict of interest.
}

How to cite this article: Corazzi V, Accorona R, Negro R, et al. Late relapse in the neck: considerations from a case of seminoma and review of the literature. Acta Otorhinolaryngol Ital 2020;40:313315. https://doi.org/10.14639/0392-100X-N0488

(c) Società Italiana di Otorinolaringoiatria e Chirurgia Cervico-Facciale

\section{(c) (i) $(9$}

This is an open access article distributed in accordance with the CC-BY-NC-ND (Creative Commons Attribution-NonCommercial-NoDerivatives 4.0 International) license. The article can be used by giving appropriate credit and mentioning the license, but only for non-commercial purposes and only in the original version. For further information: https:// creativecommons.org/licenses/by-nc-nd/4.0/deed.en 
Definitive histologic features showed epithelioid round cells with round ovular nuclei and scarce cytoplasm, and necrotic material interposed (Fig. 1B). The neoplasia showed intense nuclear positivity for the SALL-4 gene (Fig. 1C), nuclear and cytoplasmic positivity for OCT3/4 (Fig. 1D), both markers for germ cells tumours; it was therefore consistent with metastasis from seminoma in 6 of 24 excised nodes.

The patient underwent to adjuvant second-line cisplatinbased chemotherapy. Follow-up at 6 months showed no evidence of disease.

The patient agreed to the publication of clinical data.

In differential diagnosis of neck masses in adults, malignant tumours represent the most common cause, and neck involvement may frequently be the initial or unique clinical manifestation. Work up includes patient's oncologic history, clinical and endoscopic head and neck (H\&N) examination, UADT, US with FNAC, contrast enhanced $\mathrm{CT}$ and/or magnetic resonance imaging (MRI), and PET.

CUP cervical node metastases account for almost $3 \%$ of all $\mathrm{H} \& \mathrm{~N}$ malignancies ${ }^{1}$. About $65-70 \%$ of cases are due to squamous cell carcinoma (SCC) metastases from the $\mathrm{H} \& \mathrm{~N}$ district, especially when level II and, less frequently, I and III are involved. Tonsil and tongue base HPV-related SCC are reported to be the most common primaries responsible for CUP neck metastases ${ }^{2}$. Papillary thyroid carcinoma should also be considered, since it may present level II to IV metastases as primary and/or unique clinical manifestations ${ }^{1}$.

CUP metastases in the low cervical nodes are rarer, and, among $\mathrm{H} \& \mathrm{~N}$ subsites, commonly derived from nasopharyngeal and skin cancers, particularly when level $\mathrm{V}$ is involved ${ }^{1}$.

Besides H\&N cancers, levels IV and V are occasionally affected by metastases from tumours originating below the clavicle, such as breast, lung, gastrointestinal tract, kidney and genitourinary tract cancers ${ }^{1,3}$.

Remote primary tumours are responsible for about $1 \%$ of all cervical node metastases. Breast cancer is the most frequent distant primary, even if only $2.3-4.3 \%$ of cases metastasise to the neck ${ }^{4}$. Trans-pectoral, internal mammary, and axillary routes are described as principal lymphatic drainage pathways from breast to low cervical nodes ${ }^{5}$. Among lung cancers, large cell carcinomas and adenocarcinomas are reported to be the most affecting cervical nodes, with lymphatic metastases that can reach the neck along the mediastinal chains.

Oesophageal carcinomas, both SCC and adenocarcinoma, and gastric cancers, predominantly adenocarcinomas, may metastasise to the neck, with predilection for left levels IV and $\mathrm{V}$. The submucosal lymphatic plexus of the oesophagus
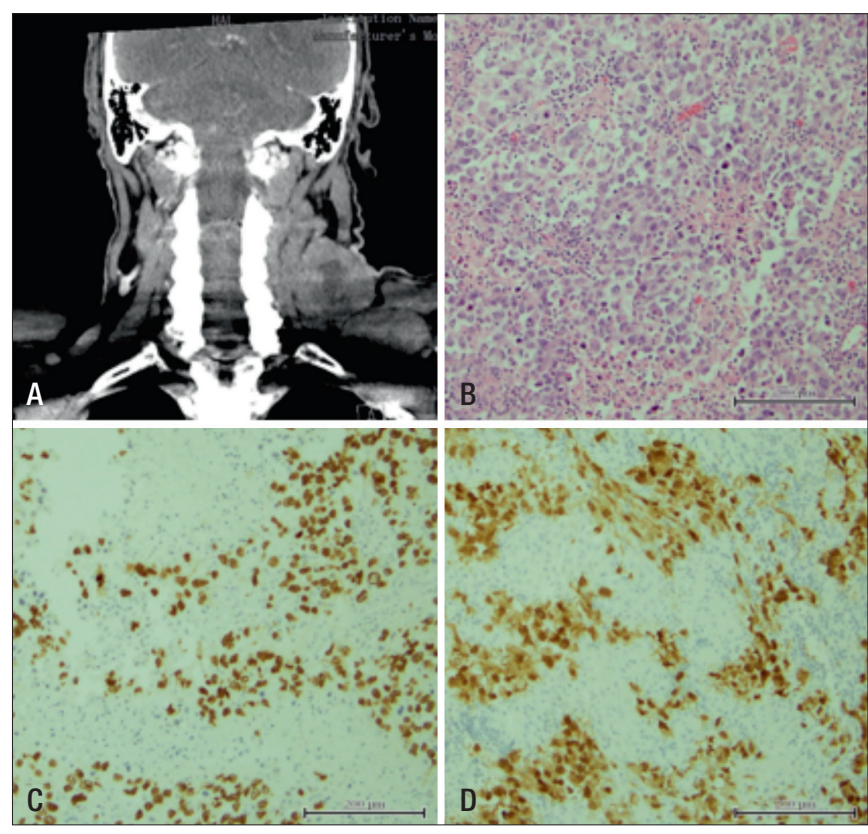

Figure 1. (A) Coronal contrast enhanced CT showing a colliquated adenopathy in the left level VB; (B) definitive histologic features showing epithelioid round cells with round ovular nuclei and scarce cytoplasm, and necrotic material interposed; (C) intense nuclear immunohistochemical expression of SALL-4; (D) immunohistochemical staining of nuclear and cytoplasmic OCT-3/4.

seems to be linked to the thoracic duct; indeed, up to 20 $30 \%$ of oesophageal carcinomas show neck metastases. The lymphatic pathway from the stomach passes through hepatic and splenic chains, celiac plexus, and porta hepatis up to the thoracic duct, with a tendency to involve the left supraclavicular area. This peculiar adenopathy is known as Virchow's node ${ }^{4}$. Moreover, supraclavicular metastases have been reported only rarely in hepatocellular cancer and, anecdotally, in gastrinomas ${ }^{4}$.

From the genitourinary tract, renal cancer is the third distant primary tumour responsible for neck metastases in frequency; cervical involvement may occur in $8 \%$ of patients at initial presentation or many years after primary treatment. The haematogenous pathway through Batson's venous plexus directed to neck nodes, without lung involvement, is reported to be more common compared to lymphatic spread ${ }^{4}$.

With low and uneven frequency, neck metastases from uterine, ovarian, prostate and testicular cancers have been reported. Ovarian cancers may determine cervical metastases at initial presentation and during recurrence, but generally after long time, with up to 20 years reported. In males, supraclavicular metastases may occur during progression of a prostate and testicular cancer, or as the first presentation of disease mainly in younger patients ${ }^{4}$. With regards to our case, seminoma is a malignant germ cells tumour that accounts for about $60 \%$ of germ cells tumours 
of the testicle and for $30 \%$ of all testicular tumours ${ }^{6}$. Involvement of mediastinal and/or supraclavicular nodes is a manifestation of advanced systemic disease; lymphatic spread follows the abdominal retroperitoneal chains above the diaphragm along the thoracic duct, up to the left supraclavicular and scalene nodes ${ }^{7}$.

Late relapses of seminoma have been described as recurrences more than 2 years after complete response to initial therapy, in the absence of a contralateral tumour ${ }^{8}$. Sharp reported 75 patients who were affected by late relapse of testicular germ cell tumours, mostly in the retroperitoneum; only 9 presented relapse at more than 15 years after initial treatment, and only 5 cases in the entire sample were seminoma, showing the low prevalence of the disease ${ }^{8}$. To the best of our knowledge, late relapse of seminoma to cervical nodes after more than 20 years from the primary treatment is a unique finding in the literature.

FNAC represents the foremost exam for a cervical mass, and immunochemistry helps to confirm clinical suspicion ${ }^{9}$, even if correct diagnostic definition of a cervical cystic mass may be hampered by the high rate of false negatives with FNAC. Distinguishing a cystic metastasis from branchial cyst or infectious disease (such as tuberculosis or abscess) may not be easy. Differential diagnosis of neck masses should always consider inflammatory, infectious and congenital disorders. Additional tests such as complete blood count, autoantibodies, thyroid and parathyroid function tests, Mantoux test and Bartonella titre may also be useful ${ }^{10}$.

In conclusion, late neck lymph node metastasis is a rare occurrence in the natural history of distant cancers. The work up of cancer of unknown primary remains challenging; nonetheless, in case of positive clinical data, cancers of remote sites should always be considered in the differential diagnosis of low neck adenopathies with unknown primary, even many years after the primary treatment.

\section{References}

1 Strojan P, Ferlito A, Medina JE, et al. Contemporary management of lymph node metastases from an unknown primary to the neck: I. A review of diagnostic approaches. Head Neck 2013;35:123-32. https:// doi.org/10.1002/hed.21898

2 Galloway TJ, Ridge JA. Management of squamous cancer metastatic to cervical nodes with an unknown primary site. J Clin Oncol 2015;33:3328-37. https://doi.org/10.1200/JCO.2015.61.0063

3 Pisani P, Airoldi M, Allais A, et al. Metastatic disease in head \& neck oncology. Acta Otorhinolaryngol Ital 2020;40(Suppl. 1):S1-S86. https://doi.org/10.14639/0392-100X-suppl.1-40-2020

4 López F, Rodrigo JP, Silver CE, et al. Cervical lymph node metastases from remote primary tumor sites. Head Neck 2016;38(Suppl 1):E2374-85. https://doi.org/10.1002/hed.24344

5 Tanis PJ, Nieweg OE, Valdés Olmos RA, et al. Anatomy and physiology of lymphatic drainage of the breast from the perspective of sentinel node biopsy. J Am Coll Surg 2001;192:399-409. https://doi. org/10.1016/s1072-7515(00)00776-6

6 Akst LM, Discolo C, Dipasquale B, et al. Metastatic seminoma with cervical lymphadenopathy as the initial manifestation. Ear Nose Throat J 2004;83:356-9.

7 Ferlito A, Shaha AR, Buckley JG, et al. Metastatic cervical lymph nodes from urogenital tract carcinoma: a diagnostic and therapeutic challenge. Acta Otolaryngol 2001;121:556-64.

8 Sharp DS, Carver BS, Eggener SE, et al. Clinical outcome and predictors of survival in late relapse of germ cell tumor. J Clin Oncol 2008;26:5524-9. https://doi.org/10.1200/JCO.2007.15.7453

9 Ota Y, Iihara K, Ryu T, et al. Metastatic seminomas in lymph nodes: CD10 immunoreactivity can be a pitfall of differential diagnosis. Int J Clin Exp Pathol 2013;6:498-502.

10 Pynnonen MA, Gillespie MB, Roman B, et al. Clinical practice guideline: evaluation of the neck mass in adults. Otolaryngol Head Neck Surg 2017;157(Suppl 2):S1-S30. https://doi. org/10.1177/0194599817722550 